Document downloaded from:

http://hdl.handle.net/10251/161837

This paper must be cited as:

Vercher Sanchis, J.; Fombuena, V.; Díaz, A.; Soriano Cubells, MJ. (2020). Influence of fibre and matrix characteristics on properties and durability of wood-plastic composites in outdoor applications. Journal of Thermoplastic Composite Materials. 33(4):477-500. https://doi.org/10.1177/0892705718807956

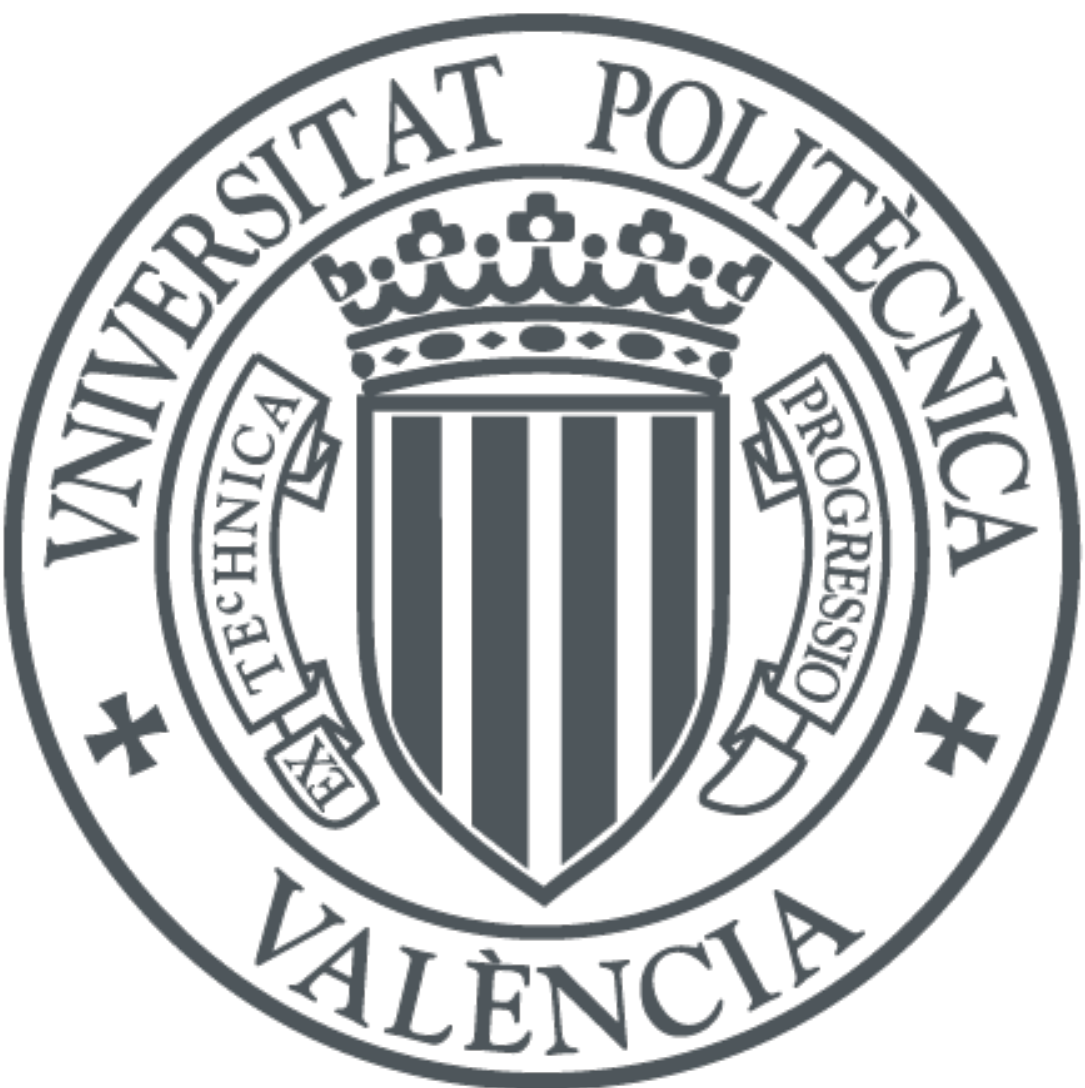

The final publication is available at

https://doi.org/10.1177/0892705718807956

Copyright SAGE Publications

Additional Information 


\title{
Influence of fiber and matrix characteristics on properties and durability of Wood Plastic Composites in outdoor applications
}

\author{
Jose Vercher ${ }^{\mathrm{a},{ }^{*}}$, Vicent Fombuena ${ }^{\mathrm{b}}$, Arturo Diaz ${ }^{\mathrm{a}}$, Maria Soriano ${ }^{\mathrm{a}}$ \\ aDepartment of Architectural Constructions, Universitat Politècnica de València - UPV, Camino de Vera s/n, 46022 \\ Valencia, Spain \\ bInstituto de Tecnología de Materiales - ITM, Universitat Politècnica de València - UPV, Camino de Vera s/n, 46022 \\ Valencia, Spain \\ *Corresponding author. E-mail address: jvercher@csa.upv.es (Jose Vercher).
}

\begin{abstract}
The awareness of society on environmental issues has increased in recent years. This paper focuses on the Wood Plastic Composites (WPCs), obtained from recycled plastics and natural fibres waste, and their application in architecture. In order to give some recommendations to architects regarding the choice of a WPC as an alternative to wood for uses in outdoor decking, a series of standardized physical, mechanical and chemical tests have been carried out on two commercial WPC materials: one with a polyvinyl chloride - PVC matrix and rice husk filler and a second one with a polyethylene - PE matrix and pine wood reinforcement. Mechanical, thermal and ageing behaviour of these commercial WPC has been broadly studied. This research provides value information to find out which WPC material best support durability aspects, those that most concern in an architectural application of outdoor decking. In general terms, WPC developed by PVC matrix and rice husk as filler shown greater physical-mechanical properties, better resistance to chemical agents and greater resistance to ageing behaviour and changes in visual aspect.
\end{abstract}

\section{Keywords}

Composite, Polymer, Fibre reinforcement, Mixture proportion, Weathering.

\section{Introduction}

The awareness of society on environmental issues has increased in recent years. Concepts such as recycle, reuse, reduce and energy saving are gaining importance in obtaining products under a clearly defined objective of a sustainable development. The revaluation of agroforestry waste has established itself as a solution to the problems associated with these wastes and, increasingly, is being incorporated into the manufacture of new materials.

Fossil fuels used as the main source of multiple applications are highly polluting, in addition to being a non-renewable resource, susceptible to exhaustion in the medium or short term. Plastic materials and polymer matrix composites have traditionally been made from petroleum-derived polymers. It is necessary to use new renewable sources for its manufacture with a positive contribution on the sustainable development. In the legal field, there are already laws that affect producers and force them to take charge of their waste. It is also important to keep in mind that most industrial wastes, although they are no longer useful for its main use, could serve to other industrial products, as it is the case of natural filler in polymer composites.

In response, the industry and the scientific community have promoted projects and initiatives for the development of new materials and products of high environmental performance. This change covers many industrial sectors, including the automotive and transportation sector, along with the construction and packaging sector, among others [1]. 
In the context of composites, based on the combination of several components to achieve a synergistic effect, the research is directed towards the use of components of renewable origin, both in the polymeric materials that act as matrices, as in the components that are incorporated for reinforcement/filler [2]. In this sense arise the 'green composites' or 'biocomposites' as alternative materials to the widespread use of plastics and classical composites obtained from petroleum products.

Wood Plastic Composites (WPC) are composite materials consisting primarily of a polymer matrix, generally thermoplastic, and a reinforcement/filler from wood by-products, in the form of small fibers or flour.

The most common thermoplastic matrices are commodities such as polyethylene (PE), polypropylene (PP), polyvinyl chloride (PVC) and polystyrene (PS), due to cost reasons of materials and ease of processing. Nevertheless, the main drawback of these petroleum-derived polymers is their non-biodegradability leading to a waste generation at the end of the life cycle. Considering the significant advances being made in the plastics sector, it is important to highlight the increasing use of plastics from renewable resources and/or biodegradable (disintegrable in controlled compost soil). It is worth to note the increasing use of polylactic acid (PLA), thermoplastic starches (TPS) and other polysaccharides [3] as well as bacterial polymers such as polyhydroxyalkanoates (PHAs) [4]. In addition to these, some petroleum-based polyester polymers such as polybutylene succinate (PBS), poly( $\varepsilon$-caprolactone) (PCL), polybutylene adipate-co-terephthalate (PBAT), can be disintegrated in controlled compost soil and their use in the field of wood plastic composites (WPCs) is continuously increasing as environmentally friendly solutions to other materials.

The most widely known and used natural-organic fillers are wood flour and fibers. Wood flour can be easily and cheaply obtained from sawmill wastes and it is usually used after proper sieving. Wood fibers are produced by thermo-mechanical processes on wood waste [5]. Besides wood derivatives, other natural-organic fillers have begun to find application as well. Among these, some examples are derived from plants and as such cotton, flax [6-7], sisal [8-9], kenaf, jute [10], hemp, starch, coconut, nut shells, almond skin [11], sugar palm [12], abaca, leaf fibres, bamboo [13], rice, wheat straw etc. and even eggshell [14], posidonia oceanica [15] or biochar [16].

With the use of these new matrices and lignocellulosic fillers of different origin, the concept of WPC is extended to that of NFRP, Natural Fiber Reinforced Plastics, which comprises composite materials formed by a thermoplastic matrix and a lignocellulosic type-reinforcing element [17]. In this case, as shown in the previous bibliography, a wide variety of research is related to the study of new WPC. However, the study of commercially available WPCs on the market today is scarce. Given the problem of choosing a material for architectural applications, the only information available are the technical specifications of the producers. In addition, it is a considerable problem if one takes into account that there are more than 100 manufacturers linked to the WPC, including leading companies and referrals in the domestic and international market [18]. Markets are growing, and although Europe started late in this field, significant countries like France or Germany already appear, with annual growths above $30 \%$. In more mature markets such as the United States, current growth is around 25\%, and in Japan it is over 60\% [19].

The use of these new materials in construction is mainly oriented towards outdoor products, such as technological decking, cladding, fencing, lattices and in urban furniture elements such as benches, litter bins and pergolas. Because of their sound insulation properties, some other applications have been proposed [20].

In this paper, influence of two different polymeric matrix as PVC and PE and two different fillers as rice's husk and pine wood, has been studied by mechanical properties (Shore D Hardness, Charpy's Impact Test, Flexural strength), thermo-mechanical properties (Vicat Softening Temperature, and thermomechanical analysis), as well as ageing behaviour and possible visual 
aspect changes, in order to give some recommendations to architects regarding the choice of a WPC as an alternative to wood for uses in outdoor decking.

\section{Materials and methods}

In this research, a series of standardized physical, mechanical and chemical tests have been carried out [21-22] on two commercial WPC materials with different matrices and lignocellulosic fillers. The first one is composed of polyvinyl chloride (PVC) and husk rice while the second one is mainly composed of a polyethylene (PE) matrix and pine wood sawdust. The only application of the evaluated WPC products, kindly supplied by two manufacturers, is outdoor decking, which seeks the best behavior for this architectural use. The response of these materials provides valuable information of their behaviour and more relevant for use as outdoor decking properties.

The tested specimens were selected in order to assess the variation in the behavior of the WPC with the polymer type, the polymer percentage and the type of reinforcement/filler (wood waste or shell). The two commercial WPCs were supplied in the form of extruded profiles for decking uses. The WPC labelled as PE35-WF65 is composed of polyethylene $(35 \mathrm{wt} \%)$ and pine wood sawdust (65 wt\%). On the other hand, the WPC coded as PVC50-RH50 refers to a polyvinyl chloride of $50 \mathrm{wt} \%$ and a filler content of $50 \mathrm{wt} \%$ (husk rice flour).

As per April 2014 the European Norm (EN) 15534 [23] was introduced into the EU-member countries. Developed by the Mirror Committee CEN/TC 249/WG 13: wood-polymer composites (WPC), this norm specifies compounds, which are made from natural fibres, mixed with polymeric plastics [24]. EN 15534 Part 4 [25] is focused on the application of decking profiles. The EN 15534 gives information on which standard to use for each test. The authors have carried out various tests (sun test, climatic chamber, salt mist, water absorption and chemical degradation) that in some occasions did not have specific standards to perform them in these materials, searching the assessment of durability against various atmospheric agents.

\subsection{Physical-Mechanical behaviour}

\subsubsection{Shore hardness}

The hardness was measured according to EN ISO 868 [26] in a durometer model 676-D from JBot Instruments. The objective of this test is to determine the hardness of penetration of plastics and ebonite by means of two types of durometers, type A for softer materials and type D for harder materials. In this work the type D method was used since WPCs of both polyethylene (PE) and polyvinyl chloride (PVC) can be considered as hard materials.

\subsubsection{Charpy impact properties}

This property is important to determine the impact resistance of materials, which is a key parameter in building applications, so other authors have studied it before [27-28]. The test procedure according to EN ISO 179-1 [29] indicates that a horizontal specimen must be placed between standard supports and struck with a normalized mass by a single oscillation of a pendulum. A Charpy pendulum from Metrotec was used to measure the impact resistance. The Charpy impact strength of non-notched specimens, $a_{c U}$, is expressed in $\mathrm{kJ} / \mathrm{m}^{2}$, and was calculated as follows:

$$
a_{c U}=\frac{E_{c}}{h \cdot b} \times 10^{3}
$$

where $E_{c}$ is the corrected energy absorbed at the rupture of the specimen, in $\mathrm{J}, h$ is the specimen thickness, in $\mathrm{mm}$, and $b$ stands for the specimen width, in $\mathrm{mm}$.

\subsubsection{Flexural strength}

The flexural strength was assessed in accordance with EN ISO 178 [30] in a universal test machine ELIB 30 from SAE Ibertest. This test gives valuable information about mechanical performance of the tested material. Test specimens are prepared from commercial products in accordance with 
EN ISO 2818 [31]. These must have parallel faces and surfaces and edges free of scratches and burrs [32]. Specimens that break outside the central third between supports should be rejected. The flexural failure stress, $\sigma_{\mathrm{f}}$, was calculated as:

$$
\sigma_{f}=\frac{3 F L}{2 b h^{2}}
$$

where $F$ is the applied force, in $\mathrm{N}, L$ is the distance between supports, in $\mathrm{mm}, b$ is the specimen width, in $\mathrm{mm}$, and $h$ is the specimen thickness, in $\mathrm{mm}$.

Flexural strain, $\varepsilon_{f}$,was also obtained according EN ISO 178 [30], as follows:

$$
\varepsilon_{f}=\frac{600 s h}{L^{2}} \%
$$

where $s$ stands for the vertical displacement in the center of the span, in $\mathrm{mm}, h$ is the specimen thickness, in $\mathrm{mm}$, and $L$ is the distance between supports, in $\mathrm{mm}$.

As in other works [33-36], the surface morphology of the impact-fractured samples was investigated by scanning electron microscopy (SEM) analysis to assess the potential polymerparticle interactions. A field emission scan electron microscope (FESEM) model ULTRA 55 (ZEISS), with an acceleration voltage of $3 \mathrm{kV}$ was used to examine the fracture morphology of the composite samples. A direct observation of the material surface by SEM reveals its topography and allows us to estimate the causes that have produced the failure, as well as the analysis of the microstructure of the material.

\subsection{Thermal behaviour - Stability}

\subsubsection{Vicat softening temperature}

The purpose of this test is to determine the temperature at which a normalized penetrator with a standard force is introduced $1 \mathrm{~mm}$ onto the surface of a test specimen. The penetrator exerts a specific perpendicular force on the specimen, while the specimen is heated at a specific and uniform velocity. This temperature indicates the temperature at which the tested thermoplastic begins to soften.

Vicat softening temperature was measured in accordance with EN ISO 179-1 [37] in a Vicat/HDT station VHDT 20 from Metrotec S.A. According to this standard, four methods can be used for the determination of Vicat temperature. The method used in this research is the second one, method $\mathrm{B} 50$, in which a force of $50 \mathrm{~N}$ and a heating rate of $50^{\circ} \mathrm{C} / \mathrm{h}$ are used.

\subsubsection{Coefficient of linear thermal expansion}

The coefficient of linear thermal expansion (CLTE) was obtained using a Q400 thermomechanical analyser (TMA) from TA Instruments. The applied force was $0.02 \mathrm{~N}$ and a constant nitrogen flow $(50 \mathrm{~mL} / \mathrm{min})$ was used. A dynamic program from $-20{ }^{\circ} \mathrm{C}$ to $20{ }^{\circ} \mathrm{C}$ at a constant heating rate of $2{ }^{\circ} \mathrm{C} / \mathrm{min}$ was used to measure the CLTE. Prior to the dynamic program, a stabilizing isothermal program at $-20{ }^{\circ} \mathrm{C}$ for 5 min was used. According to ISO 11359-2 [38], the value of the coefficient of linear thermal expansion, $\alpha$, between the temperatures $T_{1}$ and $T_{2}$ for a specimen with initial length of $L_{0}$ at the reference temperature $T_{0}$ is:

$$
\alpha=\frac{\Delta L}{\Delta T} \cdot \frac{1}{L_{0}}
$$

where $\Delta L=L_{2}-L_{1}$, and $\Delta T=T_{2}-T_{1}$, being $L_{2}$ and $L_{1}$ the lengths of the specimen at $T_{2}$ and $T_{1}$ temperatures respectively.

\subsection{Behaviour against external agents}

\subsubsection{Artificial weathering 'sun test' - colorimetry}

Artificial and natural UV-weathered WPCs have been evaluated in other investigations [39-40] due to the importance for an outdoor application. In this research, standards EN ISO 4892-3 [41] 
and UNE 53104 [42] were used to evaluate the accelerated ageing caused by ultraviolet (UV) radiation, with the aim of analysing the damage due to the sun in the WPCs.

The objective of the test is to simulate at laboratory scale the photo degradation processes that occur in the outdoor. As UV radiation is highly harmful for plastics, a UVA 340 lamp, which simulates the solar radiation in a shorter time and allows evaluating the damage, was used to follow the ageing process (Fig. 1a [43]).

[insert Figure 1.] Fig. 1. (a) Spectral irradiance of a typical UVA-340 lamp (type 1A) compared to the total solar radiation of CIE Publication No. 85, where 1 is the total solar radiation according to CIE, and 2 is the spectral irradiance of a typical UVA-340 lamp (type 1A); (b) Specimens exposed to the UVA-340 lamp.

The UV light generated by the fluorescent UV lamp is about $5 \%$ of the solar spectrum radiation, so that 1-hour exposure to sunlight equates to approximately $1.2 \mathrm{~min}$ UV light with the lamp used in this test. In this test, samples were exposed for 6 hours to the UV lamp, which is equivalent to about 300 hours of exposure to the sun, or what is the same for 30 sunny days.

Subsequently, a colorimeter was used to quantify surface discoloration due to ageing. Colour measurements were conducted in a Hunter Mod. CFLX-DIF-2 colorimeter from Hunterlab, adapted to colour-data software. Because the initial colour of the specimen is determinant in the colour variation, samples of light and dark hue were tested in the two assessed types of WPC.

Colour measurement of composites was analysed per EN ISO 11664-4 [44]. It was determined by calculating the CIELAB discolouration $(\Delta E)$ of the weathered samples in terms of lightness $\left(L^{*}\right)$ and chromaticity $\left(a^{*}\right.$ and $\left.b^{*}\right)$ of unweathered and weathered specimens. The equation is given as:

$$
\Delta E_{a b}^{*}=\left[\left(\Delta L^{*}\right)^{2}+\left(\Delta a^{*}\right)^{2}+\left(\Delta b^{*}\right)^{2}\right]^{1 / 2}
$$

Where $\Delta L^{*}, \Delta a^{*}$, and $\Delta b^{*}$ are the difference of initial and final values of the colour coordinates $L^{*}, a^{*}$ and $b^{*} . L^{*}$ ranges from 0 (black) to 100 (white) while $a^{*}$ (red-green) and $b^{*}$ (yellow-blue) are interpreted as: $+a$ expresses redness, $-a$ expresses greenness, $+b$ expresses yellowness and $b$ expresses blueness [45].

The colorimeter gives us another very important data, the yellowing index $(Y I)$, which indicates the change in color of a sample from white to yellow.

\subsubsection{Resistance to ageing by climatic chamber}

This test was performed to assess the influence of extreme weather conditions on WPC samples. There is not any standard for this test in this type of materials. The test procedure was performed by introducing the samples into the climatic chamber (CCK-25/480 from Dycometal) under an isothermal temperature of $75{ }^{\circ} \mathrm{C}$ and $90 \%$ relative humidity (RH) for one month and evaluating their modifications once removed from the chamber.

\subsubsection{Resistance to ageing by salt mist}

In the absence of a specific standard for composites, the standard for natural stone [46] was used to assess the resistance of WPCs to salt mist, since it will provide relevant information for outdoor decking near the coast, where there is saline mist exposure.

Two daily cycles consisting on 4 hours of wetting and 8 hours of drying were carried out, with a concentration of sodium chloride of $100 \mathrm{~g}$ per liter of water. The test consists of $60 \mathrm{cycles}$, with a visual inspection every 15 cycles. The test was performed at a constant temperature of $35{ }^{\circ} \mathrm{C}$ and at a saturated humidity of $100 \%$.

\subsubsection{Water absorption}

The test procedure is performed by immersing the dried specimens in distilled water. Samples were dried in a vacuum oven at $23{ }^{\circ} \mathrm{C}$ for $4 \mathrm{~h}$, cooled in a desiccator, and then immediately 
weighed to the nearest $0.001 \mathrm{~g}$. Then, samples were immersed in distilled water and maintained at $23{ }^{\circ} \mathrm{C}$.

Water absorption $(W A)$ of the WPCs was determined according to EN ISO 62 [47], with the following equation:

$$
W A=\frac{W_{t}-W_{0}}{W_{0}} x 100
$$

where $W_{0}$ is the mass of the sample after drying and prior to immersion, in $\mathrm{mg}$, and $W_{t}$ is the mass of the sample after immersion at the pre-determined time $\mathrm{t}$, in $\mathrm{mg}$.

\subsection{Chemical behaviour - Degradation}

\subsubsection{Chemical resistance to commonly used products}

In this work, the behaviour of the WPCs in outdoor decking is evaluated. Therefore, it is necessary to study their behavior against the chemical agents that can be spilled out on them.

This test was conducted following the standard for agglomerated stone [48], since there is not any standard that regulates this type of test for WPC-type composites.

The objective of the test was the determination of the chemical and stain resistance after prolonged contact with aggressive chemical agents, potentially capable of reacting with the surface of the material, penetrating or altering its appearance in any way. Following the recommendations in Annex A, the potential damage caused by chemical dyestuffs that could come into contact with the surface of the material was estimated.

The test procedure was performed by applying a chemical agent to the material, allowing it to act for one hour, after which it is washed with water. Then the surface and the stain left by the selected chemical agent was observed. In previous tests, ten chemical agents with a reasonable contact probability with the WPC were proposed, given the use in outdoor decking. These ten agents were foods and drinks (mayonnaise, ketchup, olive oil, lemon juice and coffee), cleaning products (ammonia, diluted hydrochloric acid, detergent and bleach) and others (sun cream).

\section{Results and discussion}

\subsection{Evaluation of the physical-mechanical behaviour}

As it was supposed, the introduction of a filler subtly reduces the values of the mechanical strengths with respect to the base polymers.

\subsubsection{Shore hardness}

Five hardness measurements should be performed at different positions of the samples, with a separation of at least $6 \mathrm{~mm}$, and the average value determined. Two specimens of each material were tested, obtaining the results of Table 1.

Table 1

Shore hardness type D

\begin{tabular}{llllllllll}
\hline Sample & \multicolumn{2}{c}{$\begin{array}{l}\text { Shore hardness } \\
\text { Point 1 }\end{array}$} & Point 2 & Point 3 & Point 4 & Point 5 & Average & $\begin{array}{l}\text { Total } \\
\text { average }\end{array}$ & $\begin{array}{l}\text { Coeff. } \\
\text { variation }\end{array}$ \\
\hline PE35-WF65 & 1 & 69 & 71 & 70 & 65 & 70 & 69 & 69 & $3 \%$ \\
& 2 & 70 & 71 & 67 & 66 & 71 & 69 & & $3 \%$ \\
PVC50-RH50 & 3 & 75 & 75 & 76 & 75 & 74 & 75 & 74.5 & $0.8 \%$ \\
& 4 & 75 & 74 & 75 & 72 & 74 & 74 & & $1.5 \%$ \\
\hline
\end{tabular}


The best behavior regarding Shore hardness is found for samples made with PVC, given the strong additivation of these plastics and the higher content of plastic. It is important to keep in mind that hardness not only depend on the polymer matrix but also on the type and amount of lignocellulosic filler. PVC is much harder than PE. This is a direct consequence of the chemical structure of both. PVC is a brittle polymer with a glass transition temperature $\left(\mathrm{T}_{\mathrm{g}}\right)$ of about $85-90{ }^{\circ} \mathrm{C}$ which means that PVC behaves as a glass material (high resistance and brittleness) below this temperature. On the other hand, $\mathrm{PE}$ is a flexible polymer at room temperature since its $\mathrm{T}_{\mathrm{g}}$ is of about $-120^{\circ} \mathrm{C}$. Despite these differences, the overall hardness is also dependent on the nature and amount of the lignocellulosic filler. With regard to the two WPCs evaluated in this work, although the PVCbased WPC contains less filler load (50 wt\%) than the PE-based WPC (65 wt $\%)$, the overall hardness is higher for PVC-WPC as PVC is remarkably much harder than PE. This property is important because it reflects the resistance of the material to penetration by other objects, so it is a simple way of estimating the mechanical performance of a WPC.

\subsubsection{Charpy impact properties}

The dimensions of the tested specimens and average values of Charpy impact strength are shown in Table 2.

Table 2

Dimensions of the tested samples for Charpy impact and average impact strength values

\begin{tabular}{lllllll}
\hline Sample & $\mathrm{h}(\mathrm{mm})$ & $\mathrm{b}(\mathrm{mm})$ & $1(\mathrm{~mm})$ & $\mathrm{h} \cdot \mathrm{b}\left(\mathrm{mm}^{2}\right)$ & $E_{c}(\mathrm{~J})$ & $a_{c U}\left(\mathrm{~kJ} / \mathrm{m}^{2}\right)$ \\
\hline PE35-WF65 & 5.76 & 11.25 & 78.05 & 64.80 & 0.30 & 4.63 \\
PVC50-RH50 & 5.29 & 12.30 & 79.81 & 65.07 & 1.04 & 15.98 \\
\hline
\end{tabular}

The behavior for the PVC50-RH50 samples is significantly better. As in the previous case, this material shows a greater energy absorption because of the introduced reinforcement, finely divided rice husk, which improves the energy absorption against the wood fibers. Impact strength is a mechanical property directly related to the ability of a material to absorb energy during the fracture process. The effects of the energy absorption are elastic and plastic deformation. This property highly depends on the material cohesion. Unfilled polymers tend to show higher impact resistance than their filled counterparts. An unfilled polymer shows a full continuity and this allows energy absorption during deformation and fracture, as microcracks are difficult to form. On the other hand, filled-polymers show high discontinuity (lower cohesion) due to the finely dispersed particles into the polymer matrix. In general, lignocellulosic particles are highly hydrophilic due to presence of hydroxyl groups in cellulose. On the other hand, polymers are usually hydrophobic. This difference is responsible for low polymer-particle interactions which in turn, lead to poor cohesion thus resulting in brittle materials. In this case, although both materials possess different polymer matrix, the PE-based WPC possesses higher load content and this is important enough to provide lower impact resistance than that offered by the PVC-based WPC.

\subsubsection{Flexural strength}

The values of the assessed specimens of each material are in Table 3 and show the better behavior in the flexural strength test for the PE35-WF65 samples, with respect to the PVC50-RH50 samples. The distance between supports was $100 \mathrm{~mm}$ in all tests. Flexural strength is a mechanical resistant property that is directly related to the hardness and the overall cohesion. The maximum deflection (vertical displacement) is higher for the PE-based WPC as PE is a more flexible polymer than PVC.

Table 3

Dimensions of the tested samples and flexural strength values

\begin{tabular}{llllllllll}
\hline Sample & $\mathrm{b}$ & $\mathrm{h}$ & $\mathrm{b} \cdot \mathrm{h}$ & Failure \\
$(\mathrm{mm})$ & $(\mathrm{mm})$ & $\begin{array}{l}\text { Vertical } \\
\left(\mathrm{mm}^{2}\right)\end{array}$ & $\begin{array}{l}\text { Flexural } \\
\text { displac. } \\
(\mathrm{N})\end{array}$ & $\begin{array}{l}\text { Flexural } \\
(\mathrm{mm})\end{array}$ & $\begin{array}{l}\text { Average } \\
(\%)\end{array}$ & $\begin{array}{l}\text { Coeff. } \\
\text { stress }\end{array}$ & $\begin{array}{l}\text { flexure } \\
\text { variation }\end{array}$ \\
\hline
\end{tabular}




\begin{tabular}{lllllllllll}
\hline & & \multicolumn{1}{c}{ (MPa) } & \multicolumn{2}{c}{$\begin{array}{l}\text { failure } \\
\text { stress }\end{array}$} \\
\hline PE35-WF65 & 1 & 14.44 & 6.00 & 86.64 & 246 & 7.51 & 2.70 & 70.98 & 70.59 & $0.5 \%$ \\
& 2 & 13.55 & 5.85 & 79.27 & 217 & 5.97 & 2.10 & 70.19 & & \\
PVC50-RH50 & 3 & 13.50 & 8.50 & 114.75 & 468 & 4.02 & 2.05 & 71.97 & 68.63 & $4.9 \%$ \\
& 4 & 13.45 & 8.42 & 113.25 & 415 & 3.13 & 1.58 & 65.28 & & \\
\hline
\end{tabular}

Fig. 2 shows the typical load-vertical displacement curves of the different specimens tested to flexure.

[insert Figure 2.] Fig. 2. Load-vertical displacement curves, where 1 and 2 are PE35-WF65 samples and 3 and 4 are PVC50-RH50 samples.

An analysis of the fractured surfaces from flexural tests can be useful to support overall mechanical performance of the studied WPCs, as well as to deeply study the interaction between natural fiber and composite matrix. Fig. 3a shows the general appearance of the breakage for PE35-WF65 samples, in which the directionality of the extrusion process used in the processing of the plate is appreciated. The distribution of the wood fibers on the surface and the plasticization of the polymer between them can also be seen. In Fig. 3b, the wood fiber was analysed at higher magnification. In Fig. 3c, the breakage for PVC50-RH50 samples can be seen. The different appearance of the rice husk with respect to wood fiber is clear. Fig. 3d shows the good arrangement of the rice husk crushed particles and homogeneously mixed with the PVC. This good blend of reinforcement and matrix provides the excellent mechanical behavior observed in the tests. This good interaction between filler and polymeric matrix, besides to being samples with high contents of loads $(50 \%)$, it implies to the authors that these materials have been previously treated to increase the compatibility between the charge, hydrophilic, and the hydrophobic matrix. However, the producer of the materials does not specify what type of treatment has been carried out.

[insert Figure 3.] Fig. 3. SEM images of fractured WPCs from flexural tests: (a) PE35-WF65 25x; (b) PE35-WF65 150x; (c) PVC50-RH50 25x; (d) PVC50-RH50 2500x.

\subsection{Evaluation of the thermal behaviour}

\subsubsection{Vicat softening temperature}

Table 4 shows the Vicat Softening Temperature (VST) values of the samples tested. These softening indices show that the material made with PVC has a higher temperature than PE composite. This should be taken into account in the process of extrusion of the products that are made with them, as well as in their possibilities of surface finishes and textures to achieve for their uses. The Vicat softening point or VST is equivalent to a hardness test with increasing temperature. The higher VST values are representative for more resistance to heat. As it has been previously mentioned, $\mathrm{PVC}$ is much harder than $\mathrm{PE}$ and, obviously, as the temperature increases, the difference is still higher. For this reason, the PVC-WPC shows a VST value of $109.4^{\circ} \mathrm{C}$ which is remarkably higher than that of the PE-based WPC. This value indicates that the PE-WPC needs $85.1^{\circ} \mathrm{C}$ to soften enough to allow a fixed penetration while the PVC-based WPC, despite its lower filler content, needs higher temperature to reach the same penetration level, thus indicating its superior thermomechanical performance. In the case to use this two WPC at room temperature, the hardness of samples are higher than showed in Table 4, however trend observed will be the same, when PVC-WPC values higher than PE-WPC.

Table 4

Vicat Softening Temperature (VST) values

\begin{tabular}{lllll}
\hline Sample & & VST $\left({ }^{\circ} \mathrm{C}\right)$ & $\begin{array}{l}\text { Average } \\
\text { VST }\left({ }^{\circ} \mathrm{C}\right)\end{array}$ & $\begin{array}{l}\text { Coeff. of } \\
\text { variation }\end{array}$ \\
\hline PE35-WF65 & 1 & 85.6 & 85.1 & $0.6 \%$ \\
& 2 & 84.6 & & \\
PVC50-RH50 & 3 & 109.6 & 109.4 & $0.2 \%$ \\
& 4 & 109.2 & & \\
\hline
\end{tabular}




\subsubsection{Coefficient of linear thermal expansion}

Table 5 indicates the coefficient of linear thermal expansion (CLTE) values achieved with the tested materials. Fig. 4 presents the variation of this coefficient and its estimate for both materials in the temperature range tested. This value must be taken into account for the design of joints with both materials, since their behaviour is very different. The CLTE provides a direct measurement of the dimensional stability as a function of temperature. This parameter is directly related to other mechanical resistant properties as well as the filler load. Nevertheless, it seems that once again, the polymer matrix plays a key role in dimensional stability. Results obtained shown as PVC has lower CLTE than PE, concretely $41 \%$ lower. This behaviour is related with two main aspects: the polymeric matrix used and the amount of filler employed. In this case, glass transition $\left(\mathrm{T}_{\mathrm{g}}\right)$ of $\mathrm{PVC}$ is around $85-90^{\circ} \mathrm{C}$, while in the case of $\mathrm{PE}$ is around $-120^{\circ} \mathrm{C}$. This aspect, besides to lower amount of filler employed in the PVC WPC, confer this polymeric composite, greater thermal and dimensional stability than PE WPC. The PE35-WF65 specimens exhibit almost twice the expansion of PVC50-RH50, so this material would have a greater variation of thermal, geometrical and mechanical properties as a function of temperature.

Table 5

Results of linear thermal expansion experiments

\begin{tabular}{lll}
\hline & PE35-WF65 & PVC50-RH50 \\
\hline Initial temperature $\left({ }^{\circ} \mathrm{C}\right)$ & -20.99 & -15.98 \\
Final temperature $\left({ }^{\circ} \mathrm{C}\right)$ & 20.99 & 20.9 \\
Initial variation $(\mu \mathrm{m})$ & -23.57 & -12.00 \\
Final variation $(\mu \mathrm{m})$ & 1.31 & 1.47 \\
Coefficient of linear thermal & 90.09 & 52.21 \\
expansion $\left(\mu \mathrm{m} /\left(\mathrm{m}\left({ }^{\circ} \mathrm{C}\right)\right)\right.$ & &
\end{tabular}

[insert Figure 4.] Fig. 4. Variation of the coefficient of linear thermal expansion. Comparison between PE35-WF65 and PVC50-RH50 samples.

\subsection{Evaluation of the behaviour against external agents}

\subsubsection{Artificial weathering 'sun test'- colorimetry}

Clear and dark specimens of each studied WPC were tested, due to the influence of sample tone in its discoloration. In this way, six samples of PE35-WF65_light, PVC50-RH50_light, PE35WF65_dark and PVC50-RH50_dark were prepared in order to assess the sun weathering over time. An hour of exposure to $\overline{U V}$ fluorescent lamp is approximately equivalent to 5 days of exposure to sun. Colorimetry at exposure times 1/2,1,2, 4 and 6 hours was studied.

Fig. 5 shows the record of the effect of the sun light degradation of the samples tested as a function of the exposure time, reaching the equivalence of one month of exposure to the sun.

Prior to the test, the parameters necessary for the colorimetry were taken at 5 different points in each sample, and the average values calculated. Likewise, the colorimetric values in the different stages of the test were measured in different 5 points in each specimen and the average value was calculated. The average results of colorimetry before, during and after 'sun test' artificial weathering experiments are shown in Table 6 and Fig. 6.

[insert Figure 5.] Fig. 5. Photographic record of samples subjected to light degradation.

In view of the results, it should be noted that in the light samples, although they have different composition, the loss of lightness in the PE sample is almost double that in the sample made with PVC. This is due to the strong additivation in colorants that the PE needs to achieve that tone. In the case of dark samples, a maintenance of the lightness values during the exposure time is observed, although the composition is different. The strong addition of incorporated dyes makes their behavior very similar regardless of the employed polymer.

The chromaticity values $a$ and $b$ in the clear samples suffer a more remarkable change in the PE sample than in the PVC sample. This effect is also due to the incorporated additives to obtain the 
clear tone of imitation to the color of the natural wood. As with lightness, a certain maintenance of the chromaticity values during the exposure time is seen in the dark tone samples. Small differences between them are attributed to the different formulation of the WPC.

Table 6

Average results of colorimetry during 'sun test' artificial weathering experiments

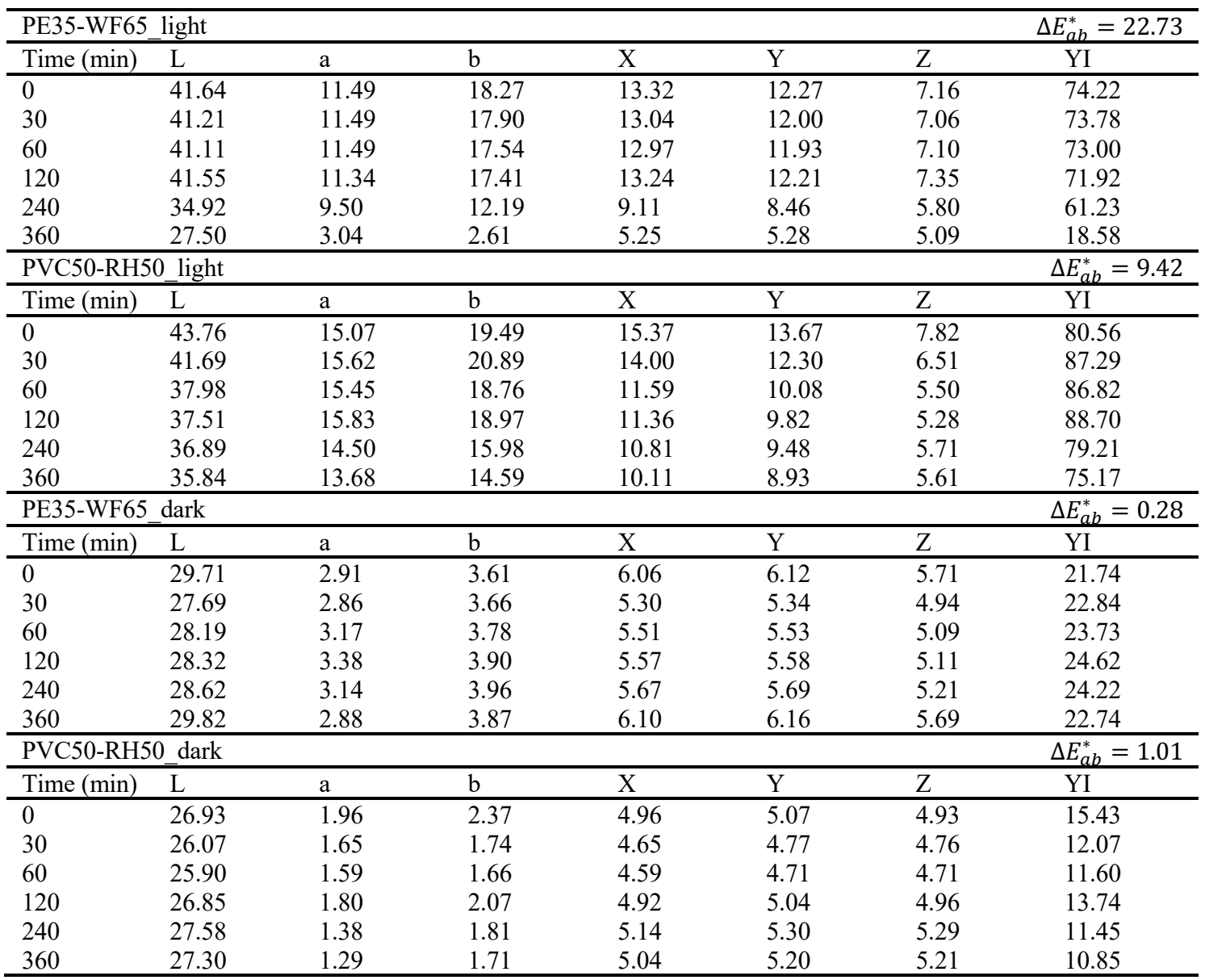

The $Y I$ colorimetric parameter represents the yellowing tone of plastics and is generally highly relevant since most plastics are usually whitish or transparent. The evolution of this parameter is similar to the previous ones. The sample PE35-WF65_light has a more remarkable decrease than the sample PVC50-RH50_light, due to the strong additivation of the PVC. Yellowing index, $A I$, is maintained for dark samples, although in the case of sample PVC50-RH50_dark is more accused.

[insert Figure 6.] Fig. 6. Colorimetric parameters as a function of time during UV fluorescent lamp ageing: (a) Lightness $L$; (b) Chromaticity $a$; (c) Chromaticity $b$; (d) Yellowing index $Y I$.

\subsubsection{Resistance to ageing by climatic chamber}

This test, in which 3 samples of each WPC material were tested, is performed to assess the effects of extreme weather conditions on WPC products. The specimens were subjected to a high temperature and relative humidity $(\mathrm{RH})$ inside a climatic chamber during one month, and later they were taken out to study their change in appearance and dimensions.

Table 7

Dimensions of the tested samples before and after the climatic chamber test and dimensional change

\begin{tabular}{lllll}
\hline Sample & \multicolumn{3}{l}{ Dimensions before the test } \\
& $\mathrm{b}(\mathrm{mm})$ & $\mathrm{h}(\mathrm{mm})$ & $1(\mathrm{~mm})$ \\
\hline PE35-WF65 & 1 & 83.05 & 50.20 & 25.25 \\
& 2 & 111.60 & 42.20 & 19.40
\end{tabular}




\begin{tabular}{|c|c|c|c|c|}
\hline \multirow{5}{*}{ PVC50-RH50 } & & & & \\
\hline & 3 & 98.10 & 42.20 & 19.40 \\
\hline & 4 & 72.95 & 45.65 & 27.10 \\
\hline & 5 & 115.45 & 50.95 & 27.10 \\
\hline & 6 & 115.45 & 52.45 & 27.10 \\
\hline & & \multicolumn{3}{|c|}{ Dimensions after the test } \\
\hline & & $\mathrm{b}(\mathrm{mm})$ & $\mathrm{h}(\mathrm{mm})$ & $1(\mathrm{~mm})$ \\
\hline \multirow[t]{3}{*}{ PE35-WF65 } & 1 & 83.55 & 50.25 & 26.00 \\
\hline & 2 & 113.55 & 42.20 & 20.25 \\
\hline & 3 & 98.95 & 42.20 & 20.25 \\
\hline \multirow[t]{3}{*}{ PVC50-RH50 } & 4 & 73.65 & 45.75 & 27.20 \\
\hline & 5 & 116.10 & 51.05 & 27.20 \\
\hline & 6 & 116.05 & 53.10 & 27.20 \\
\hline & & \multicolumn{3}{|c|}{ Dimensional change } \\
\hline & & $\mathrm{b}$ & $\mathrm{h}$ & 1 \\
\hline \multirow[t]{3}{*}{ PE35-WF65 } & 1 & $0.6 \%$ & $0.1 \%$ & $2.9 \%$ \\
\hline & 2 & $1.7 \%$ & $0 \%$ & $4.3 \%$ \\
\hline & 3 & $0.8 \%$ & $0 \%$ & $4.3 \%$ \\
\hline \multirow[t]{5}{*}{ PVC50-RH50 } & 4 & $0.9 \%$ & $0.2 \%$ & $0.4 \%$ \\
\hline & 5 & $0.6 \%$ & $0.2 \%$ & $0.4 \%$ \\
\hline & 6 & $0.5 \%$ & $1.2 \%$ & $0.4 \%$ \\
\hline & & \multicolumn{3}{|c|}{ Averaged value of dimensional change } \\
\hline & & $\mathrm{b}$ & $\mathrm{h}$ & 1 \\
\hline \multirow{2}{*}{\multicolumn{2}{|c|}{$\begin{array}{l}\text { PE35-WF65 } \\
\text { PVC50-RH50 }\end{array}$}} & $1 \%$ & $0 \%$ & $3.8 \%$ \\
\hline & & $0.7 \%$ & $0.5 \%$ & $0.4 \%$ \\
\hline \multicolumn{5}{|c|}{ Standard deviation } \\
\hline PE35-WF65 & & 0.51 & 0.05 & 0.76 \\
\hline PVC50-RH50 & & 0.14 & 0.47 & 0 \\
\hline
\end{tabular}

Table 7 contains the dimensions of the tested specimens before and after the test. It can be seen that the dimensional change was practically insignificant. Very few measures vary more than $1 \%$.

As regards the change in appearance, it is necessary to indicate that a clear yellowing of the samples was visually observed after the test.

\subsubsection{Resistance to ageing by salt mist}

After performing the ageing by salt mist test, the most remarkable thing is the presence of surface salts in the samples corresponding to the darker tones of PVC50-RH50. There is not weathering in the light samples.

\subsubsection{Water absorption}

Water absorption (WA) values obtained for PE35-WF65 and PVC50-RH50 samples at controlled conditions of humidity and temperature $\left(50 \% \mathrm{RH}\right.$ at $\left.23{ }^{\circ} \mathrm{C}\right)$ are presented in the Table 8 . Four samples of each WPC material were assessed in order to study the 24 hours and 7 days water absorption. Water absorption behaviour of WPCs as a function of immersion time is shown in Fig. 7.

PE35-WF65 samples absorb more water than samples PVC50-RH50. As the percentage of natural fibers increases higher water absorption values were obtained. The water absorption is directly related to the total content on lignocellulosic filler. In fact, although PE is more hydrophobic than PVC, the results indicate that the WPC with higher lignocellulosic fillers offers higher water uptake. It is important to keep in mind that cellulose possesses a high number of hydroxyl groups $(-\mathrm{OH})$ that can readily interact with water thus resulting in water absorption. This is one of the main drawbacks that WPCs have and is partially solved by using compatibilizers or surface treatments that block the hydroxyl groups in cellulose, thus avoiding their reaction with water. Therefore, it is important to maintain the finishes and hydrophobic textures of the material surface of the PVC50-RH50 samples.

A good way to study the durability is through the water immersion test. Most of the absorption occurs during the first 24 hours, resulting in reduced values, which indicates that although this 
test is maintained for 5-6 months, these values should not exceed 8-10\%, as different authors have studied. Values obtained lower than $6 \%$ are common in WPC with high lignocellulosic content [49]. It is important to remark that commonly accepted water uptake in wood products is $25 \%$ moisture content; this represents the minimum level necessary to start a decrease in mechanical properties and bacterial growth [50].

Table 8

Results of water absorption tests

\begin{tabular}{|c|c|c|c|c|c|c|c|}
\hline \multirow[t]{2}{*}{ Sample } & & \multicolumn{6}{|c|}{ Water absorption (24 hours) } \\
\hline & & $\mathrm{M}_{1}(\mathrm{~g})$ & $\mathrm{M}_{2}(\mathrm{~g})$ & $\mathrm{M}_{2}-\mathrm{M}_{1}(\mathrm{~g})$ & WA $(\%)$ & Average WA (\%) & Coeff. of variation \\
\hline \multirow[t]{2}{*}{ PE35-WF65 } & 1 & 28.84926 & 29.51279 & 0.66359 & 2.30 & 2.38 & $3 \%$ \\
\hline & 2 & 26.39787 & 27.04461 & 0.64674 & 2.45 & & \\
\hline \multirow[t]{4}{*}{ PVC50-RH50 } & 3 & 19.92510 & 20.12634 & 0.20124 & 1.01 & 1.03 & $1.9 \%$ \\
\hline & 4 & 20.02034 & 20.23056 & 0.21022 & 1.05 & & \\
\hline & & \multicolumn{6}{|c|}{ Water absorption (7days) } \\
\hline & & $\mathrm{M}_{1}(\mathrm{~g})$ & $\mathrm{M}_{2}(\mathrm{~g})$ & $\mathrm{M}_{2}-\mathrm{M}_{1}(\mathrm{~g})$ & WA $(\%)$ & Average WA (\%) & Stand. dev. \\
\hline \multirow[t]{2}{*}{ PE35-WF65 } & 5 & 43.42553 & 45.91816 & 2.49273 & 5.74 & 5.84 & $1.7 \%$ \\
\hline & 6 & 26.22798 & 27.78330 & 1.55532 & 5.93 & & \\
\hline \multirow[t]{2}{*}{ PVC50-RH50 } & 7 & 37.36741 & 38.75132 & 1.38391 & 3.70 & 3.73 & $0.8 \%$ \\
\hline & 8 & 37.54805 & 38.95986 & 1.41181 & 3.76 & & \\
\hline
\end{tabular}

[insert Figure 7.] Fig. 7. Results of water absorption experiments

\subsection{Evaluation of the chemical behaviour - Degradation}

\subsubsection{Chemical resistance to commonly used products}

Considering the use of outdoor decking of these materials, a series of aggressive chemical agents with the possibility of being spilled out on the material throughout its useful life were selected. In previous tests, the deterioration caused by cleaning products (ammonia, diluted hydrochloric acid, detergent and bleach), foods and drinks (mayonnaise, ketchup, olive oil, coffee and lemon juice) and others (sun cream) were analyzed. Some of these agents do not seem to affect the material, since when cleaning with abundant water the surface of the material, the initial stain disappeared. The definitive tests were carried out with the agents in which the stain remained: sun cream, lemon juice, diluted hydrochloric acid and coffee.

The surface was carefully cleaned with blotting paper before proceeding to the test. The aggressive agent was placed on the surface with the aid of a pipette. The test procedure is shown in Fig. 8. For an elapsed time of $30 \mathrm{~min}$, it can be observed how each agent is acting on the material. Some of them lost the surface tension of the initial drop, in others a capillarity was observed towards the interior and others clearly manifested a reaction with the material. According to the standard EN 14617-10 [48], the samples were visualized after eight hours. In the PE samples, all four products left a residue, as can be seen in Fig. 8. The only agent left on the PVC sample was the sun cream. This could be related to the fact that lignocellulosic filler is highly hydrophilic. In the case of PE-based WPC, with a lignocellulosic content of $65 \mathrm{wt} \%$, the carrier liquid penetrates the material through the natural filler particles thus leading to a final staining at $8 \mathrm{~h}$. With regard to the PVC-based WPC, it contains less filler load (50 wt\%) and this could be responsible for lowering the ability of the chemicals to penetrate.

[insert Figure 8.] Fig. 8. Degradation by common chemical agents

\section{Conclusions}

In this study, two different WPC materials were assessed in order to evaluate their outdoor decking application. Through physical, chemical and mechanical tests, the best behavior for each property has been determined. These tests have allowed comparing the behavior of two very different types of WPC in their formulation with respect to the polymer used (polyethylene or polyvinyl chloride) and with respect to the added fibers (pine wood fibers or rice husk residues). 
These commercial WPC products for decking have adequate properties to meet the loading/environmental/durability requirements for decking, according to EN 15534-4 [25]. The pieces of WPC for outdoor decking do not usually fail due to mechanical reasons, due to the characteristic constructive detail used for their installation. The possible main cause of the fall of these materials is the behavior against external agents (sun, temperature, water and attacks of bacteria to lignocellulosic materials), what changes the colour. Based on the performed analyses, the main findings of this research can be summarized as follows:

- The physical-mechanical behavior of the tested samples indicates a better performance of the PVC-based WPC against the PE-based WPC. This best behavior has been assessed by higher values of some mechanical properties such as Shore hardness, impact resistance and flexural strength. Both PVC and PE are polymers classified as thermoplastics. However, the better mechanical behavior of PVC, due to its particular structure, leads to parallel better properties, even with lower filler content than the PE-based WPC. On the other hand, the better adhesion in the interface between polymer and rice husk residues compared to the interface between polymer and wood fiber has contributed to improve the results as well.

- The coefficient of linear thermal expansion was significantly higher in the material formulated with PE, which demonstrates the influence of the type of polymer on the possible dimensional variations in service of these composite materials. It is important to remark, that usually, natural fillers tend to restrict thermal expansion in polymers but the higher thermal expansion of PE versus PVC is enough to give composites with higher CLTE even though the PE-based WPC contains higher filler load.

- In the 'sun test', a notable loss of luminance is observed. This is mainly due to the stability of the pigments, dyes and processing additives used in the formulation of the plastic matrices. Given the need for them in the PE, this kind of WPC is the material that is most affected in this test in the light tones that imitate natural wood.

- When samples are subjected to accelerated ageing test in a climatic chamber, with exposure conditions for a month at a constant temperature $75^{\circ} \mathrm{C}$ and a relative humidity of $90 \%$, some discoloration appeared. This discoloration is due to the ageing of the polymers present in the WPC formulation. This discoloration is barely perceived in some tones, so they are recommended in applications for more severe exposures.

- A slight residue of low-adhered salts is manifested in the dark tone samples for the two assessed WPC materials when subjecting the specimens to the salt mist test. Because of this, it is advisable to use light tones in coastal exposure applications.

- Water absorption is significantly higher in the WPC with wood fiber compared to that containing rice husk residues. The water uptake in WPCs is directly related to their cellulose and hemicellulose content. Cellulose and hemicellulose contains a high number of hydroxyl groups that can readily react with moisture and water thus leading to water absorption. Each natural filler contains different weight percentages of cellulose, hemicellulose, lignin and other extractives. So that, the water uptake depends on both parameters: composition and total content of the lignocellulosic filler.

- PVC composites have better resistance to common chemical agents. This is due in part to the high additivity of this plastic to favor its processing, and in the case of the WPCs for use as outdoor decking, the need to create powerful hydrophobic surfaces. The four most aggressive agents leave residue in the WPC with PE, whereas only the sun cream leaves permanent residue in the WPC with PVC.

\section{Acknowledgements}

The authors acknowledge the Universitat Politècnica de València, UPV, the Escuela Técnica Superior de Arquitectura de València, ETSAV, and the Escuela Politecnica Superior de Alcoy, EPSA, for their support of this work allowing us to use their facilities. This research did not 
receive any specific grant from funding agencies in the public, commercial, or not-for-profit sectors.

\section{References}

[1] Arenas FJ. El impacto ambiental en la edificación. Criterios para una edificación sostenible. 1st ed. Madrid: Edisofer, 2007, p.248.

[2] Miravete A. Los nuevos materiales en la construcción. 1st ed. Barcelona: Reverté, 1995, p. 394.

[3] Kaseem M, Hamad K, Deri F, et al. Material properties of polyethylene/wood composites: A review of recent works. Polym Sci Ser A 2015; 57[6]: 689-703.

[4] Najafi SK, Hamidinia E and Tajvidi M. Mechanical properties of composites from sawdust and recycled plastics. J Appl Polym Sci 2006; 100: 3641-3645.

[5] La Mantia FP and Morreale M. Green composites: A brief review. Compos: Part A 2011; 42: 579-588.

[6] Mahboob Z, El Sawi I, Zdero R, et al. Tensile and compressive damaged response in Flax fibre reinforced epoxy composites. Compos: Part A 2017; 92: 118-133.

[7] Paynel F, Morvan C, Marais S, et al. Improvement of the hydrolytic stability of new flaxbased biocomposite materials. Polym Degrad Stab 2013; 98: 190-197.

[8] Badia JD, Kittikom T, Strömberg E, et al. Water absorption and hydrothermal performance of PHBV/sisal biocomposites. Polym Degrad Stab 2014; 108: 166-174.

[9] Alvarez VA and Vazquez A. Thermal degradation of cellulose derivates / starch blends and sisal fibre biocomposites. Polym Degrad Stab 2004; 84: 13-21.

[10] Liu L, Yu J, Cheng L, et al. Biodegradability of poly(butylene succinate) (PBS) composite reinforced with jute fibre. Polym Degrad Stab 2009; 94: 90-94.

[11] Valdés A, Ramos M, Beltran A, et al. Characterization and degradation characteristics of poly( $\varepsilon$-caprolactone)-based composites reinforced with almond skin residues. Polym Degrad Stab 2014; 108: 269-279.

[12] Sanyang ML, Sapuan SM, Jawaid M, et al. Recent developments in sugar palm (Arenga pinnata) based biocomposites and their potential industrial applications: A review. Renew Sustain Energy Rev 2016; 54: 533-549.

[13] Abdul Khalil HPS, Bhat IUH, Jawaid M, et al. Bamboo fibre reinforced biocomposites: A review. Mater Des 2012; 42: 353-368.

[14] Boronat T, Fombuena V, Garcia-Sanoguera D, et al. Development of a biocomposite based on green polyethylene biopolymer and eggshell. Mater Des 2015; 68: 177-185.

[15] Macia A, Baeza F, Saval JM, et al. Mechanical properties of boards made in biocomposites reinforced with wood and Posidonia oceanica fibers. Compos: Part B 2016; 104: 1-8.

[16] Das O, Bhattacharyya D, Hui D, et al. Mechanical and flammability characterisations of biochar/polypropylene biocomposites. Compos: Part B 2016; 106: 120-128.

[17] Fowler PA, Hughes JM and Elias RM. Review biocomposites: technology, environmental credentials and market forces. $J$ Sci Food Agric 2006; 86: 1781-1789. 
[18] Danyadi L, Janecska T, Szabo Z, et al. Wood flour filled PP composites: Compatibilization and adhesión. Compos Sci Technol 2007; 67: 2838-2846.

[19] Gurunathan T, Mohanty S and Nayak SK. A review of the recent developments in biocomposites based on natural fibres and their application perspectives. Compos: Part A 2015; 77: $1-25$.

[20] Zhu X, Kim BJ, Wang Q, et al. Recent advances in the sound insulation properties of biobased materials. BioResources 2014; 9[1]: 1764-1786.

[21] Tascioglu C, Tufan M, Yalcin M, et al. Determination of biological performance, dimensional stability, mechanical and thermal properties of wood-plastic composites produced from recycled chromated cooper arsenate-treated wood. J Thermoplast Compos Mater 2014; 29 : 1461-1479.

[22] Bhaskar J, Haq S and Yadaw SB. Evaluation and testing of mechanical properties of wood plastic composite. J Thermoplast Compos Mater 2011; 25: 391-401.

[23] EN 15534-1: 2014. Composites made from cellulose-based materials and thermoplastics (usually called Wood-Polymer Composites (WPC) or Natural Fiber Composites (NFC)) - Part 1: Test methods for characterization of compounds and products.

[24] Friedrich D and Luible A. Investigations on ageing of wood-plastic composites for outdoor applications: A meta-analysis using empiric data derived from diverse weathering trials. Constr Build Mater 2016; 124: 1142-52.

[25] EN 15534-4: 2014. Composites made from cellulose-based materials and thermoplastics (usually called Wood-Polymer Composites (WPC) or Natural Fiber Composites (NFC)) - Part 4: Specifications for decking profiles and tiles.

[26] EN ISO 868: 2003. Plastics and ebonite. Determination of indentation hardness by means of a durometer (Shore hardness).

[27] Gourier C, Bourmaud A, Le Duigou A, et al. Influence of PA11 and PP thermoplastic polymers on recycling stability of unidirectional flax fibre reinforced biocomposites. Polym Degrad Stab 2017; 136: 1-9.

[28] Pickering KL, Aruan Efendy MG and Le TM. A review of recent developments in natural fibre composites and their mechanical performance. Compos: Part A 2016; 83: 98-112.

[29] EN ISO 179-1: 2000. Plastics. Determination of Charpy impact properties. Part 1: Noninstrumented impact test.

[30] EN ISO 178: 2010. Plastics. Determination of flexural properties.

[31] EN ISO 2818: 1996. Plastics. Preparation of test specimens by machining.

[32] EN ISO 294-1: 1998/A1: 2002. Plastics. Injection moulding of test specimens of thermoplastic materials. Part 1: General principles, and moulding of multipurpose and bar test specimens.

[33] Muthuraj R, Misra M, Defersha F, et al. Influence of processing parameters on the impact strength of biocomposites: A statistical approach. Compos: Part A 2016; 83: 120-129.

[34] Gil-Castell O, Badia JD, Kittikorn T, et al. Hydrothermal ageing of polylactide/sisal biocomposites. Studies of water absorption behaviour and Physico-Chemical performance. Polym Degrad Stab 2014; 108: 212-222. 
[35] Campos A, Marconcini JM, Martins-Franchetti SM, et al. The influence of UV-C irradiation on the properties of thermoplastic starch and polycaprolactone biocomposite with sisal bleached fibers. Polym Degrad Stab 2012; 97: 1948-55.

[36] Azwar E, Vuorinen E and Hakkarainen M. Pyrolysis-GC-MS reveals important differences in hydrolytic degradation process of wood flour and rice bran filled polylactide composites. Polym Degrad Stab 2012; 97: 281-287.

[37] EN ISO 306: 2004. Plastics. Thermoplastic materials. Determination of Vicat softening temperature (VST).

[38] ISO 11359-2: 1999. Plastics. Thermomechanical analysis (TMA). Part 2: Determination of coefficient of linear thermal expansion and glass transition temperature.

[39] Soccalingame L, Perrin D, Benezet JC, et al. Reprocessing of artificial UV-weathered wood flour reinforced polypropylene composites. Polym Degrad Stab 2015; 120: 313-327.

[40] Soccalingame L, Perrin D, Benezet JC, et al. Reprocessing of artificial UV-weathered wood flour reinforced polypropylene composites: Study of a natural outdoor exposure. Polym Degrad Stab 2016; 133: 389-398.

[41] EN ISO 4892-3: 2016. Plastics. Methods of exposure to laboratory light sources. Part 3: Fluorescent UV lamps.

[42] UNE 53104: 1986. Plásticos. Envejecimiento artificial acelerado de materiales plásticos. Equipo basado en lámparas fluorescentes.

[43] CIE Publication No. 85: 1989. Solar spectral irradiance.

[44] EN ISO 11664-4: 2011. Colorimetry. Part 4: CIE 1976 L*a*b colour space.

[45] Azwa ZN, Yousif BF, Manalo AC, et al. A review on the degradability of polymeric composites based on natural fibres. Mater Des 2013; 47: 424-442.

[46] EN 14147: 2003. Natural stone test methods. Determination of resistance to ageing by salt mist.

[47] EN ISO 62: 2008. Plastics. Determination of water absorption.

[48] EN 14617-10: 2012. Agglomerated stone. Test methods. Part 10: Determination of chemical resistance.

[49] Ferrero B, Fombuena V, Fenollar O, et al. Development of natural fiber-reinforced plastics (NFRP) based on biobased polyethylene and waste fibers from Posidonia oceánica seaweed. Polym Comp 2014; 36:23042.

[50] Zabel RA and Morrell JJ. Wood microbiology: Decay and its prevention. Cambridge (Massachusetts): Academic Press, 2012, p. 498. 